\title{
The Effect of an Instruction Designed by Cognitive Load Theory Principles on 7th Grade Students' Achievement in Algebra Topics and Cognitive Load
}

\author{
Aygil Takir ${ }^{1}$, Meral Aksu \\ ${ }^{1}$ Turkish Education Association, Ankara, Turkey \\ ${ }^{2}$ Faculty of Education, Department of Educational Sciences, Middle East Technical University (METU), \\ Ankara, Turkey \\ Email: aygilt@gmail.com, aksume@metu.edu.tr
}

Received March 14 $4^{\text {th }}, 2012$; revised April $9^{\text {th }}, 2012$; accepted April $19^{\text {th }}, 2012$

\begin{abstract}
The purpose of this study was to investigate the effect of an instruction designed by the Cognitive Load Theory (CLT) principles on 7th grade students' achievement in Algebra topics and cognitive load. A quasi-experimental study was conducted in totally six weeks with 80 students. The instruction designed by CLT principles was used in the experimental group, while the instruction recommended by the Ministry of Education (MONE) was used in the control group. Researchers developed Teachers' Guidelines and Students' Booklets for using in the experimental group. At the end of each unit, the Subjective Rating Scale (SRS) was used to measure students' cognitive load. At the end of the treatment, the Algebra Achievement Test (AAT) was administrated to both of the groups. Both descriptive and inferential statistical techniques were used for analyzing data. Results showed that instruction designed by CLT principles was effective for the Algebra teaching with the limitations of the study.
\end{abstract}

Keywords: Cognitive Load Theory; Cognitive Load; Subjective Measure of Cognitive Load; Algebra Achievement; Efficiency of Instruction

\section{Introduction}

The Cognitive Load Theory (CLT) has emerged over the last decade as an influential theory of educational psychology and instructional design. The CLT originated in the 1980s through the work of John Sweller and his colleagues at the University of New South Wales (Clark, Nguyen, \& Sweller, 2005; Paas, Renkl, \& Sweller, 2003).

The CLT is a theoretical framework grounded in the learner's cognitive architecture (Janssen, Kirschner, Erkens, Kirschner, $\&$ Paas, 2010) that assumes that working memory (WM) is very limited in terms of being able to store and process information (Cowan, 2005; Miller, 1956; Paas, Van Gog, \& Sweller, 2010) and long term memory (LTM) has an unlimited capacity, being able to store an almost limitless amount of information. The CLT predicts learning outcomes by taking into consideration the capabilities and the limitations of this architecture (Plass, Moreno, \& Brünken, 2010).

As understood from its definition, CLT differs from other instructional theories with its emphasis on human cognitive architecture. It considers knowledge of human cognitive architecture to be critical for instructional design and effectiveness of an instruction depends heavily on whether it takes the characteristics of human cognition into account.

Cognitive load can be defined as a multidimensional construct representing the load that performing a particular task imposes on the learner's cognitive system (Paas, Tuovinen, Tabbers, \& Van Gerven, 2003; Paas \& Van Merrienboer, 1994). The roles of the WM and LTM in human architecture allow to categorize the source of the cognitive load as intrinsic, extra- neous, and germane cognitive loads (Paas et al., 2003). If load is imposed by the number of information elements and their interactivity, it is called intrinsic (ICL). If it is imposed by the manner in which the information is presented to learners and by the learning activities required of learners, it is called extraneous or germane. Whereas extraneous load (ECL) is imposed by information and activities that do not contribute to the processes of schema construction and automation; germane load (GCL) is related to information and activities that foster these processes (Paas, Renkl, \& Sweller, 2004).

There are many assessment techniques of the cognitive load. The common technique among the CLT researchers is subjective rating scale technique which is based on the assumption that "people are able to introspect on their cognitive processes and to report the amount of mental effort expended" (Paas et al., 2003). Paas and van Merrienboer (1994) have used a rating scale for measuring perceived task difficulty by using a 9-point Likert scale ranging from very, very low mental effort (1) to very, very high mental effort (9).

Efficiency is an important issue that should be considered in CLT research. It can be defined as a property of instructional products that results in faster learning, better learning, or both (Clark et al., 2005). Paas and Van Merrienboer (1993) suggests a calculation approach for combining the measures of mental load and performance that allows to obtain information on the relative efficiency of instructional conditions. Particularly, the combination of performance and cognitive load measures has been identified to constitute a reliable estimate of the cognitive efficiency of instructional methods (Paas et al., 2003). Higher learning outcomes with less cognitive effort are more efficient 
than environments that lead to lower outcomes with greater mental effort (Clark et al., 2005). To quantify the efficiency, instructional scientists Paas and van Merriënboer's (1993) use efficiency metric. Their approach provides a tool to relate cognitive effort to performance measures. In this approach, hightask performance associated with low effort is called highinstructional efficiency, whereas low-task performance with high effort is called low-instructional efficiency. This metric is calculated by subtracting cognitive load from the performance outcomes.

The CLT has generated a range of techniques intended to achieve the purpose of reducing the ECL and maximizing the GCL. CLT was applied in several contexts and studied by using randomized, controlled experiments. The empirical results of these studies led to the demonstration of several instructional techniques which are called CLT Effects. As discussed in previous paragraphs, CLT differs from the other instructional theories with its emphasis on human cognitive architecture, further; CLT differs from the other instructional theories by the methodology it uses.

There are many CLT effects that instructional designers can consider when they plan an instruction. One of them is the worked example effect which was also the main effect of this study. It is a technique that decreases the ECL by replacing some practice exercises with a series of worked examples, each followed by similar practice exercise (Clark et al., 2005). A completion problem is a partial worked example where the learner has to complete some key solution steps (Sweller, Ayres, \& Kalyuga, 2011a). It is a hybrid between practice assignment and a worked example. Like worked example, completion examples reduces cognitive load; schemas can be acquired by studying the work-out portions (Clark et al., 2005). Completion examples were used in this study especially the topics that thought to be difficult, to satisfy smooth transition from examples to practice exercises.

The basic underlined principle of the modality effect is that "complex visuals are understood more efficiently when explanatory words are presented in an audio modality than when presented in a written modality" (Clark et al., 2005). Therefore, it is very important to consider verbal explanations during the lesson hours. The redundancy effect of the CLT occurs when unnecessary, additional information is presented to learners (Sweller, 2010) or when identical information is presented in multiple forms, which decreases rather than increases learning (Pawley, Ayres, Cooper, \& Sweller, 2005). Redundancy effect is an important factor when designing instruction (Chandler \& Sweller, 1991) and, in its many forms, has a detrimental effect on learning (Kalyuga, Chandler, \& Sweller, 2001; Sweller \& Chandler, 1991). Expertise reversal effect occurs when an instructional procedure that is effective for novices in comparison to an alternative instruction that becomes less effective as expertise increases. This effect is very important especially in classrooms where there are mixture of novice and experienced learners. Expertise reversal effect has important considerations together with the guidance fading effect of the CLT. This effect suggests that learners should first be presented worked examples, followed by completion problems and then full problems assignments (Renkl \& Atkinson, 2003) which was used in this study.

As described previously, the human cognitive architecture is concerned with the manner in which cognitive structures are organized. The relations between the WM and the LTM, in conjunction with the cognitive processes that support learning, are of critical importance for designing an instruction. Kirschner et al. (2006) expressed that the architecture of the LTM provides the ultimate justification for instruction: the aim of all instruction is to alter the LTM. If nothing has changed in the LTM, nothing has been learned. They concluded that any instructional recommendation that does not specify what has been changed in the LTM, or that does not increase the efficiency with which relevant information is stored in or retrieved from the LTM, is likely to be ineffective.

From the WM perspective, Kirschner et al. (2006) described that any instructional theory that ignores the limits of WM when dealing with novel information or ignores the disappearance of those limits when dealing with familiar information is unlikely to be effective. They maintain that learners, especially novices, are unable to effectively process information due to the limits of WM, hence the learning suffers (Tobias \& Duffy, 2009).

The human cognitive architecture has obvious implications for the amount of guidance and assistance provided to the learners. Instruction should be explicit and clear. Based on this architecture, there seems to be no purpose or function to withholding information from the learners so that they can discover it for themselves (Tobias \& Duffy, 2009). According to Clark et al. (2005) the learners' engagement of an instruction is not directed toward schema acquisition and automation; so it can impose an ECL. They suggested the use of directive rather than student centered approaches for novice learners. As they stated, the instructional designers should prepare directive lessons for novice learners that provide brief content segments including explanations, examples, and practices, and further, the instructional designers should prepare more student centered lessons for more experienced learners.

The worked example, completion example, split attention, modality, expertise reversal, redundancy, and guidance faded effects of the CLT are the central CLT effects of this study and were used for preparing classroom materials and implementation process. By considering the CLT effects and human cognitive architecture principles, an instruction was designed and implemented in 7th grade Mathematics classroom. The purpose of the study was to investigate the effect of this instruction designed by the CLT principles on 7th grade students' achievement in Algebra topics and cognitive load. More specifically, the study aimed to determine whether the CLT treatment has an effect on students' Algebra achievement and cognitive load and find out the efficiency score of the instruction in terms of the students' achievement and cognitive load measures.

The study aimed to answer the following questions:

1) Does the instruction designed by CLT have significant effect on 7th grade student's Algebra achievement and cognitive load?

2) Is there a significant difference between the efficiency scores of students who were exposed to instruction designed by CLT principles compared to instruction recommended by MONE?

The following hypotheses that are stated in null form tested the research questions given above.

Null Hypothesis 1.1: There is no significant mean difference between group of students who were exposed to instruction designed by CLT principles and to instruction recommended by MONE.

Null Hypothesis 2.1: There is no significant difference be- 
tween the efficiency scores of students who were exposed to instruction designed by CLT principles and to instruction recommended by MONE.

\section{Method \\ Subjects of the Study \\ The subjects of the study were 807 th grade students in a public school in İstanbul, Turkey. 40 of the students were in classroom called 7A and the other 40 were in 7B. Groups were assigned as experimental and control randomly. General distri- bution of the subjects of the study was shown in Table 1.}

\section{Design and Procedure}

The instruction designed by the CLT effects was defined as the independent variable; students' achievement in Algebra topics and cognitive load were defined as the dependent variables. The instruction designed by CLT effects was used in the experimental group, while the instruction recommended by the Ministry of Education (MONE) was used in the control group of the study.

The study was conducted from the first week of December 2010 to 3rd week of January 2011 (totally six weeks-19 class hours). The students were assigned to classes randomly by the school administration at the beginning of the school semester. Therefore, random assignment of subjects to the experimental and control groups was not possible, and as a result, a quasiexperimental research design was utilized in the study. For the same reason, the classes were heterogeneous in terms of gender and academic achievement, and homogeneous in terms of socioeconomic status (SES), all being from low SES.

The equality of two groups defined above was controlled by comparing students' previous year mathematics achievement grades (MAG). The 6th grade mathematics achievement grades of the subjects were obtained from the grade report forms of the school records. An independent-samples t-test was conducted to control the equivalence of groups. The students' previous year mathematics grades were similar in both experimental and control groups. Both groups were taught the same mathematics content; but in experimental group, an instruction designed by the CLT principles was applied.

The study was carried out in six Algebra Units: 1) Exponents; 2) Operations on Algebraic Exponents; 3) Equations; 4) Cartesian Coordinate Plane; 5) Graphs of the First Degree Equations in One Unknown; and 6) Patterns and Relations. For each unit, the researchers developed "Teacher Guidelines" and "Student's Booklets" for using in experimental group.

\section{Students’ Booklets and Teachers' Guidelines}

Students' Booklets were developed by the researchers as classroom materials which covered all Algebraic units of the 7 th grade Mathematics curriculum. For developing each unit, the objectives of the 7 th grade mathematics curriculum and CLT effects were considered. The literature on CLT was reviewed at the beginning of the development of the student's booklets. The CLT effects used in the Student's Booklets were as follows: 1) worked example effect; 2) completion example effect; 3) split-half effect; 4) modality effect; 5) redundancy effect; and 6) guidance fading effect. Six Students' Booklets were developed together with Teachers' Guidelines.
Table 1.

Subjects of the study.

\begin{tabular}{cccc}
\hline Gender Group & $\begin{array}{c}\text { Experimental } \\
\text { Group }\end{array}$ & Control Group & Total \\
\hline Male & 19 & 20 & 39 \\
Female & 21 & 20 & 41 \\
\hline
\end{tabular}

Four mathematics teachers checked the booklets in terms of their content, appropriateness of the language used, the grade level of students, and the CLT effects. Some modifications such as wording and ordering exercises according to CLT were made according to their criticisms and suggestions. Later an expert in department of Secondary School Science and Mathematics Education controlled Students' Booklets and made some suggestions about the general view of the booklets, their content and writing form for some of the exercises.

"Teacher's Guidelines" were developed for the experimental group teacher in order to help her manage the instruction. Teacher's Guidelines were prepared by the researchers and covered the titles "explanations, duration of lesson, prerequisites of the lesson, objectives of lesson, classroom materials, and implementation of the lessons". In the "explanation" part, which effects of the CLT were used and how they were implemented were clarified for the teachers. In the "implementation of the lesson part", the implementation of the unit was explained from beginning to end by considering CLT effects and principles.

\section{Instruction in Experimental Group}

All the activities in the experimental group were prepared by using the CLT principles and effects. According to the CLT, the first step of instruction is the determination of the students' prior knowledge. The classroom was heterogeneous in terms of achievement, increasing the importance of the prior knowledge of students. This issue was related with the expertise reversal effect of the CLT. At the beginning of each lesson, the teacher asked some questions or made revisions about the topic in order to refresh the students' memory and activate their prior knowledge.

After the repetition of some prerequisite learning, for each Algebra topic, the teacher distributed Students' Booklets and carried out the lesson by following the content of the booklets. The worked examples included in booklets were the starting point of each lesson. The teacher explained each topic on the worked examples verbally (modality effect) and then assigned a similar practice exercise to the students for satisfying schema construction. The teacher gave the students enough time to complete practice exercises and always observed the classroom in order to help the students. For some Algebra topics such as Equations, the worked examples were not directly followed by the practice exercise; instead, completion examples were used. By using the completion examples, smooth transition from the worked examples to practice exercises were satisfied. Similarly, in the beginning of each lesson, the teacher explained worked examples verbally; then the teacher gave students time to complete the missing steps of the completion examples; and finally, practice exercises were assigned. The use of worked examples, completion examples, and practice exercises was related to backward fading effect of the CLT, which allowed accommodating a gradual learning process. By considering this effect, 
the WM overload was diminished.

In all Algebra topics, for satisfying the split-attention effect of the CLT, the teacher did not write anything on the board. Further, Students' Booklets were considered as content summaries and prevented note-taking for satisfying split attention effect of the CLT. Redundancy in training refers to proving more expressions of content than needed for understanding. At the beginning of each Algebra topic, any picture, extra explanation or classroom activity were not considered to satisfy the redundancy effect of the CLT. For this effect, information was presented to students through one mode; in other words, the teacher explained the content either virtually or in audio format. According to the CLT, after the students gain experience related with a topic, worked examples and completion examples become detrimental rather than beneficial for learning. For this reason, after the students gained some experience related with Algebra topics, full exercises or classroom activities/group works were assigned for the students. The same procedure was followed for all topics covered.

\section{Data Collection Instruments}

\section{Algebra Achievement Test}

Algebra Achievement Test (AAT) was developed by the researchers for determining the 7 th grade students Algebra achievement and consists of 20 open ended questions related to the Algebra topics. All questions in the test were developed by considering the objectives and content of the 7th grade Mathematics Curriculum related to the Algebra topics. The test covers the questions 1) finding value of an expression; 2) simplifying expressions; 3) writing the algebraic expression of a pattern; 4) solving equations; 5) solving problems by using equations; 6) constructing problems; 7) determining a point on Cartesian Coordinate plane; and 8) sketching graphs.

The possible scores of the test range from 0 to 80 . A rubric was created for scoring the test by the researchers. For each question, a five-score level $(0-4)$ was assigned. The highest score of 4 was awarded for responses that the researchers regard as being entirely correct and satisfactory answer, while the lowest score of 0 was reserved for no answer or completely wrong answer.

Four mathematics teachers checked the test and rubric for content validity evidence by comparing the items with the objectives. "Expert Opinion Form (EOF)" was developed for the test according to the units, objectives, and class level, and its clarity and general outlook. Moreover, the EOF was sent to the two mathematics education faculty staff to check the appropriateness, relevance, and consistency of the questions with the nature of CLT. Some revisions were made on the wording of the questions, taking into account of the experts; make them clearer and more suitable for the learning outcome being measured.

The AAT was piloted with 229, 8th grade students from three public schools in the first semester of 2009-2010 academic year. The purpose of the piloting was to check the clarity of the questions, to make sure the adequacy of the test duration, and to check reliability (internal consistency of the test). After the implementation, the researchers graded the test by taking the rubric into consideration. Upon the completion of grading by the one of the researchers, another mathematics teacher scored randomly selected 80 tests. The inter rater reliability analyses was conducted by using Statistical Package for Social Sciences (SPSS) 15.0 for Windows. Inter-rater reliability coefficient by means of intra-class correlation (ICC) was computed in order to establish the extent of consensus on the use of the scoring rubric for the test. The ICC value of the test was 0.90 , which indicated high reliability and internal consistency of scoring rubric as used by two raters.

\section{The Subjective Rating Scale of Cognitive Load}

The one item Subjective Rating Scale (SRS) developed by Paas and Van Merrienboer (1993) was used to measure students' cognitive load for both experimental and control group students. It was implemented at the end of each Algebra unit. The SRS was a 9-point symmetrical rating scale, ranging from 1 (very, very low mental effort) to 9 (very, very high mental effort). The reliability coefficient of the scale was found 0.82 by Paas and Van Merrienboer (1993). The Turkish adaptation of the scale was developed by Kılıç and Karadeniz (2004). For the translation of the test to Turkish and its clarity, Kılıç and Karadeniz took expert opinion and prepared a form for piloting (Sezgin, 2009). For the internal consistency of the test (reliability), they conducted a study and found 0.90 Cronbach Alpha reliability coefficient which was indicated as high reliability. Sezgin (2009) also conducted a study to find the internal consistency of the SRS and found 0.78 Cronbach Alpha reliability coefficient which was indicated as moderate reliability.

Performance is measured by a test taken at the end of the lesson. Cognitive load is most commonly measured by learner estimates of lesson difficulty. The difficulty (cognitive load) of lesson is assessed by using a 1 to 7 or 1 to 9 scales. In this study, performance was measured by a test taken at the end of the implementation (AAT) and cognitive load was measured by learner estimates of lesson difficulty (SRS).

\section{Results}

\section{The Descriptive Results of the Algebra Achievement Test (AAT) and Cognitive Load Scores (SRS)}

The descriptive statistics related to the student's AAT and SRS for each of the experimental and control groups are given in Table 2.

Descriptive statistics revealed that in terms of the AAT scores, the students in the experimental group $(\mathrm{M}=41.18$, SD $=12.86)$ had much higher scores than the students in the control group $(M=14.88, S D=8.28)$. In terms of the SRS scores, the experimental group students $(\mathrm{M}=3.58, \mathrm{SD}=1.55)$ had lower scores than the control group students $(\mathrm{M}=5.05, \mathrm{SD}=$ 1.39).

The mean scores of cognitive load was calculated by taking the mean of collected cognitive load data by using SRS at the

Table 2.

Mean and Standard deviation of AAT and SRS scores.

\begin{tabular}{ccccc}
\hline \multirow{2}{*}{ Groups } & \multicolumn{2}{c}{$\mathrm{AAT}^{*}$} & \multicolumn{2}{c}{$\mathrm{SRS}^{* *}$} \\
\cline { 2 - 5 } & $\mathrm{M}$ & $\mathrm{SD}$ & $\mathrm{M}$ & $\mathrm{SD}$ \\
\hline Experimental & 41.18 & 12.86 & 3.58 & 1.55 \\
Control & 14.88 & 8.28 & 5.05 & 1.39 \\
\hline
\end{tabular}

Note: ${ }^{*}$ Total score of the AAT is $80 ;{ }^{* *} 9$-point scale. 
end of each of six Algebra topics. Cognitive load score ranging between $1-4$ denotes low cognitive load and those ranging between 5 - 9 denotes high cognitive load conditions (Paas \& Van Merrienboer, 1993). According to the cognitive load ranges, there were 7 students in high cognitive load condition in the experimental group, while there were 23 students in high cognitive load condition in the control group. In contrast, there were 33 students in low cognitive load condition in the experimental group, while 17 students were in low cognitive load condition in the control group. Hence, the number of students with a high cognitive load was greater in control group than in the experimental group.

\section{Multivariate Analysis of the Variance (MANOVA): Investigation of the Effects of an Instruction Designed by CLT Principles on Students' Algebra Achievement and Cognitive Load}

MANOVA was conducted to find the answer of the research question "does the instruction designed by CLT have significant effect on 7th grade student's Algebra achievement and cognitive load?"

Prior to conducting MANOVA, the assumptions underlying this technique, namely the independence of observations, multivariate normality, homogeneity of variance-covariance, inter$\mathrm{val} /$ ratio scale on dependent variables, and outliers (Tabachnick $\&$ Fidell, 2001) were checked in order to explore the appropriateness of the data for running MANOVA.

The independence of observations assumption was met since different groups did not affect each other when answering the items in the tests used for this study.

Multivariate normality requires that the sampling distributions of the means of the dependent variables in each cell and all combinations of them are normally distributed (Tabachnick $\&$ Fidell, 2001). In order to check univariate normality assumption, skewness-kurtosis values, Q-Q plots and KolmogorovSmirnov and Shapiro-Wilk's tests were examined (Field, 2009). Skewness-Kurtosis values were not quite away from 0 for each group implied the normal distribution. The points on Q-Q plots for the cases fall along the diagonal running from lower left to upper right, with some minor deviations due to random processes implies the normality of the distribution (Tabachnick \& Fidell, 2001). The Q-Q plots of the variables indicated the normal distribution. Further, the results of the Kolmogorov-Smirnov and Shapiro-Wilk's tests also indicated the normal distribution. Mardia's test was used to examine multivariate normality. The test revealed a non-significant result indicating normal multivariate distribution.

The outliers are observations with a unique combination of characteristics identifiable as distinctly different from the other observations (Hair Jr., Anderson, Tatham, \& Black, 1995). Because MANOVA is a multivariate analysis, multivariate outliers are of special importance (Stevens, 1996). In order to examine the data for multivariate outliers, Mahalanobis Distance (D2) was used. D2 is a measure of distance in multidimensional space of each observation from the mean center of multidimensional centrality (Hair et al., 1995). The analysis revealed that the data has no cases with D2values greater than the critical values of 13.60 (2.77) for the alpha set as 0.05 . Therefore, there were no multivariate outliers.

The assumptions of homogeneity of variance and covariance is that the variance and covariance matrices within each cell of the design are sampled from the same population variancecovariance matrix and can be reasonably pooled to create a single estimate of error (Tabachnick \& Fidell, 2001).

The equality of variance assumption was satisfied by the result of the Levene's test of equality of error variances (Field, 2009). Levene's test was found to be non-significant for both Algebra achievement and cognitive load scores (Table 3).

The homogeneity of covariance matrices was checked by using Box M test (Field, 2009). Results of the Box M Test showed that homogeneity of covariance assumption was violated for the analysis, $\mathrm{F}(3,1095120)=2.70, p<0.05$. Considering the result of Box $\mathrm{M}$ and the equality of the sample cells the robustness cannot be guaranteed (Tabachnick \& Fidell, 2001). Hence, Pillai's Trace test was used instead of Wilks' Lambda to evaluate multivariate significance.

The dependent variables (AAT and SRS scores) were measured on a continuous scale, so the interval/ratio scale on dependent variables assumption was met.

The results of the MANOVA test, Pillai's Trace, was significant, $\mathrm{F}(2,77)=72.687, p<0.05$, indicating that the population means on the Algebra achievement and cognitive load scores were different for the two groups. The multivariate eta squared 0.65 indicated that 65 percent of multivariate variance of the AAT and SRS scores were associated with the group factor.

Since a significant result was obtained on the multivariate test (Table 4), it was required to check univariate analysis ANOVA in order to understand the effect of instruction on AAT and SRS scores. The results of the univariate ANOVAs are shown in Table 4. The univariate ANOVAs for AAT and SRS scores were both significant, $\mathrm{F}(1,78)=118.26, p<0.05$ and $\mathrm{F}(1,78)=19.86, p<0.05$, respectively. In terms of the variance explained, groups explained 60 percent of the variance in AAT scores whereas the groups explained 20 percent of the variance in SRS.

\section{The Results of the Efficiency of Instruction}

The second research question of the study was "is there a significant difference between the efficiency scores of students who were exposed to instruction designed by CLT principles and to instruction recommended by MONE?"

In order to quantify the effects of instruction designed by CLT principles and by MONE on students', the following efficiency formula was used (Clark et al., 2005; Paas et al., 2003).

Algebra achievement and cognitive load, the AAT and SRS scores of each subject in experimental and control group were standardized by converting z-scores (Clark et al., 2005; Paas et al., 2003). The data given in Table 5 shows the mean of AAT z-scores, SRS z-scores, and the efficiency values for both experimental and control groups calculated by the above formula (Kablan \& Erden, 2008; Paas et al., 2003; Sezgin, 2009).

To check the hypothesis that experimental group's efficiency scores of students was significantly different from the control group's efficiency scores of students; an Independent Samples t-test was conducted. The efficiency value of each student was calculated by using the above formula and putting SRS z-score and AAT z-score of each individual student on the efficiency formula. The result of the Independent Samples t-test is presented in Table 6.

The results of the Levene's test evaluate one of the assumptions of the t-test, which is whether the population variances for the two groups are equal or not. Based on the Levene's test of 
Table 3.

Levene's test of equality of error variances.

\begin{tabular}{cccc}
\hline & F & df1 & df2 \\
\hline AchScores & 2.663 & 1 & 78 \\
LoadScores & 1.530 & 1 & 78 \\
\hline
\end{tabular}

Note: ${ }^{*} p<0.05$.

Table 4.

Multivariate and univariate analysis of variance.

\begin{tabular}{cccc}
\hline \multicolumn{2}{c}{ MANOVA } & \multicolumn{2}{c}{ ANOVA } \\
\hline Variable & $\mathrm{F}(2,77)$ & $\mathrm{DV} 1 \mathrm{~F}(1,78)$ & $\mathrm{DV} 2 \mathrm{~F}(1,78)$ \\
Group & $72.687^{*}$ & $118.262^{*}$ & $19.863^{*}$ \\
\hline
\end{tabular}

Note: F ratios are Pillai's Trace approximation, DV1 = Achievement Scores, DV2 $=$ Cognitive Load Scores, ${ }^{*} p<0.05$.

Table 5.

The mean of AAT z-scores and SRS z-scores.

\begin{tabular}{cccc}
\hline Groups & $\begin{array}{c}\text { SRS z-score } \\
\text { (x-axis) }\end{array}$ & $\begin{array}{c}\text { AAT z-score } \\
\text { (y-axis) }\end{array}$ & Efficiency Value \\
\hline Experimental & -0.45 & 0.77 & 0.86 \\
Control Group & 0.45 & -0.77 & -0.86 \\
\hline
\end{tabular}

Table 6.

Results of the independent samples t-test for efficiency values of groups $(n=80)$

\begin{tabular}{ccccc}
\hline Group & $\mathrm{M}$ & $\mathrm{SD}$ & $\mathrm{t}$ & $\mathrm{df}$ \\
\hline Control & -0.86 & 0.64 & 10.339 & 78 \\
Experimental & 0.86 & 0.84 & & \\
\hline
\end{tabular}

Note: ${ }^{*} p<0.0$.

equality of variances, it can be assumed that the homogeneity of variances were not violated $(p=0.081>0.05)$ in the study.

Table 6 shows that the t-test results indicated that significant mean difference on efficiency values between the control $(\mathrm{M}=$ $-0.86, \mathrm{SD}=0.64)$ and the experimental group $(\mathrm{M}=0.86, \mathrm{SD}=$ $0.84), \mathrm{t}(78)=10.339, p<0.05$. This finding implies that there was significant difference between the efficiency values of the students in the experimental and the control group.

\section{Discussions and Conclusion}

The results indicated that the students in experimental group performed relatively well in AAT (Algebra Achievement Test) compared to the control group. The mean score of the experimental group was 41.18 and the mean score of the control group was 14.88 (out of 80). The results of the SRS (Subjective Rating Scale) indicated that the students in the experimental group had lower SRS scores than those in the control group. The mean SRS scores of the experimental and the control groups were 3.58 and 5.05 (out of 9), respectively. These results are consistent with the studies which claim that an instruction is efficient if the learning results in such a way as to maximize learning and minimize the amount of cognitive load required (Paas \& Van Merrienboer, 1994; Paas, 1992; Tuovinen $\&$ Sweller, 1999).
Although the mean AAT score of the experimental group was much higher than the control group, the mean scores of AAT for both groups were actually low. One of the reasons for these low achievement scores may be the deficiencies of the students' prior knowledge. The results indicated that the means of student's previous year mathematics scores for the experimental group $(\mathrm{M}=2.55$ out of 5$)$ and control groups $(\mathrm{M}=2.98$ out of 5) were not very high. According to the NCTM (2000) Principles and Standards, the importance of the prior knowledge was stressed as "students learn mathematics by connecting new ideas to prior knowledge... Teachers should reveal students' prior knowledge and design experiences and lessons that respond to, and build on, prior knowledge" (p. 18). Tatar and Dikici (2008) reported that one of the reasons of students' disabilities in the mathematics is the deficiencies of their prior knowledge. Therefore, it can be concluded that students' prior knowledge both in experimental and control groups effected their achievement in the AAT.

Another reason would be the socio-economic background of the students. As described in the Method section, the school that the study was conducted was located in a poor socioeconomic neighborhood. Research has consistently shown that socioeconomic status have a negative influence on students' achievement (Coleman, 1966; Engin-Demir, 2009; Heyneman \& Loxley, 1983; Savaş, Selma, \& Adem, 2010; Tansel \& Bircan, 2004). More specifically, TIMMS 98-99 data (Yayan, 2003) indicated that socioeconomic status is positively related to mathematics achievement in Turkey. Ersoy and Erbaş (1998) conducted a study to assess the Algebra achievement level of the 7 th grade students in Turkey. They found that Algebra teaching was very problematic in the poor socio-economic neighborhood. In other words, students in poor socio-economic neighborhood had lower achievement scores in Algebra topics compared to the medium or high socio-economic neighborhood.

The other reason would be the school characteristics. The physical conditions of the school that the study was conducted were quite poor in terms of school facilities and class size. Previous research indicated that school characteristics in terms of school facilities and class size had significant effect on the academic achievement of students (Engin-Demir, 2009; Fuchs \& Woessmann, 2007).

As discussed previously, the mean AAT score of the experimental group was much higher than the control group. This result indicates the success of the CLT in poor socioeconomic neighborhood. Therefore, it can be concluded that the instruction designed by the principles and effects of the CLT is successful for teaching Algebra topics in poor socio-economic neighborhood. Further, SRS scores of the students in experimental group was much lower than the SRS scores of the students in control group indicating the efficiency of the instruction designed by the principles and effects of the CLT in poor socio-economic neighborhood.

The results of the MANOVA showed that there was a significant effect. The effect size $(0.65)$ claims the practical significance of this result. It was indicated that scores of students on AAT and SRS significantly differ according to the instruction and 65 percent of multivariate variance of the AAT and SRS scores were associated with the group factor. In other words, 65 percent of the variation of the AAT and SRS scores was explained by the instruction developed by CLT principles. Similar results concerning the significant effect of the CLT 
principles had been found in several studies before (Atkinson et al., 2003; Brunstein et al., 2009; Chandler \& Sweller, 1992; Kalyuga, Chandler, \& Sweller, 2001; Kalyuga \& Sweller, 2004; Mousavi et al., 1995; Paas, 1992; Paas \& Van Merrienboer, 1994; Sweller \& Cooper, 1985; Tarmizi \& Sweller, 1988; Zhu $\&$ Simon, 1987). The results of the MANOVA suggested that the instruction developed by the CLT principles can be used in Algebra courses to increase achievement and decrease the cognitive load.

To answer second research question, the mean of the AAT z-scores, SRS z-scores, and the efficiency values for both the experimental and the control groups were calculated and put in the efficiency formula. The mean of AAT z-scores $(-0.45)$, SRS z-scores (0.77), and efficiency value (0.86) indicated that the efficiency value of the experimental group was in the second quadrant of the Cartesian Coordinate Plane, above the line $\mathrm{E}=$ 0 . As discussed before, the sign of the efficiency scores determines the efficiency; as low or high, therefore, the efficiency score of the experimental group indicated high efficiency. On the other hand, the mean of AAT z-scores $(0.45)$, SRS z-scores $(-0.77)$, and efficiency value $(-0.86)$ indicate that the efficiency value of the control group was in the fourth quadrant of the Cartesian Coordinate Plane, below the line $\mathrm{E}=0$. The efficiency score of the control group indicated low efficiency.

The results of the Independent samples t-test, $t(78)=10.339$, $p<0.05$, indicated that there was a significant difference between the efficiency scores of students who were exposed to the instruction designed by the CLT principles and those exposed to the instruction recommended by MONE. This result is consistent with the previous results that claimed that an instruction designed by the CLT are more efficient than the instructions designed by other instructional techniques (Gerven et al., 2003; Kalyuga, Chandler, \& Sweller, 2001; Van Gerven et al., 2002; Van Merriënboer, et al., 2002). Previous studies on CLT principles were mainly adapted to multimedia learning in Turkey, although, the results are still being considered for their calculation of efficiency. The results of these studies conducted by Kilıç (2006), Kablan and Erden (2008), and Sezgin (2009) indicated that the instructions prepared by the CLT principles had significantly high efficiency.

The results of this study showed that the instruction designed by CLT principles on students' achievement in Algebra topics and cognitive load was effective. Further, the efficiency value of the instruction indicated high efficiency. Therefore, the principles and CLT effects that were used in this study can be recommended to practitioners to design effective instructional environments.

The first and most important implication of an instruction designed by the CLT principles is that effective instructional environments depend on the human cognitive architecture system. Therefore, the characteristics and the principles of this system should be known well by the designers for effective instructional environments.

How the knowledge is presented to the learners and in which activities they engage in depend on the characteristics of the WM, because the WM first processes information before it is stored in the LTM. The major characteristic of the WM is its limitation, both in terms of duration and capacity. The aim of an instruction should be to ensure that the learners' WM is not overloaded. Therefore, the limitations of the WM should be well known and the instruction should be designed according to these limitations.
To manage the WM load and to facilitate LTM, the ECL (caused by poorly designed instructional procedures that interfere with schema acquisition) should be eliminated. Studying worked example has been identified by the CLT as an effective method of reducing the ECL. The learner can devote all the available WM capacity to studying a worked-out solution and constructing a schema to solve similar problems in LTM.

Worked example-problem pair instruction used in this study helped to decrease the ECL of the learners. This type of lessons alternated worked examples with a similar practice problem can be used in different instructional contexts.

The guidance fading effect of the CLT can be used especially for the novice learners who are most susceptible to cognitive overload.

Instructional designers can use guidelines for instructional methods that work best with low knowledge learners and with high knowledge learners. Instructional designers should avoid ECL when the learners are novice. As the learners develop expertise, the instructional techniques should be adjusted accordingly.

The cognitive effort required to take notes reduces cognitive capacity. Therefore, small content summaries or other supplementary materials can be provided for the learners.

The teachers can be trained or educated about the basic principles of the CLT in order to utilize the limited capabilities of the learners' WM.

\section{REFERENCES}

Atkinson, R., Renkl, A., \& Merrill, M. (2003). Transitioning from studying examples to solving problems: Effects of self-explanation prompts and fading worked-out steps. Journal of Educational Psychology, 95, 774-783. doi:10.1037/0022-0663.95.4.774

Brunstein, A., Betts, S., \& Anderson, J. R. (2009). Practice enables successful learning under minimal guidance. Journal of Educational Psychology, 101, 790. doi:10.1037/a0016656

Chandler, P., \& Sweller, J. (1991). Cognitive load theory and the format of instruction. Cognition and Instruction, 8, 293-332. doi:10.1207/s1532690xci0804_2

Clark, R., Nguyen, F., \& Sweller, J. (2005). Efficiency in learning: Evidence-based guidelines to manage cognitive load. Sydney: Pfeiffer.

Coleman, J. S. (1966). Equality of educational opportunity. Education Next, 6, 40-43.

Cowan, N. (2001). The magical number 4 in short-term memory: A reconsideration of mental storage capacity. Behavioral and Brain Sciences, 24, 87-114. doi:10.1017/S0140525X01003922

Dede, Y., \& Argün, Z. (2003). Cebir, öğrencilere niçin zor gelmektedir. Hacettepe Üniversitesi Eğitim Fakültesi Dergisi, 24, 180-185.

Dede, Y., Yalın, H. İ., \& Argün, Z., (2002). 8th grade students' mistakes on learning and misconceptions in variable concept. 5th International Science and Mathematics Education Congress, Ankara.

Engin-Demir, C. (2009). Factors influencing the academic achievement of the Turkish urban poor. International Journal of Educational Development, 29, 17-29. doi:10.1016/j.ijedudev.2008.03.003

Erbaş, A. K., \& Ersoy, Y., (2005). 9th grade students' performances and misconceptions in solving equations. Proceedings of 5 th $\mathrm{Na}$ tional Science Education Congress, Ankara

Field, A. P. (2009). Discovering statistics using SPSS. London: SAGE Publications.

Fuchs, T., \& Woessmann, L. (2007). What accounts for international differences in student performance? A re-examination using PISA data. Empirical Economics, 32, 433-464.

doi:10.1007/s00181-006-0087-0

Gerven, P. W. M., Paas, F., Merriënboer, J. J. G., Hendriks, M., \& Schmidt, H. G. (2003). The efficiency of multimedia learning into 
old age. British Journal of Educational Psychology, 73, 489-505. doi:10.1348/000709903322591208

Green, S., Salkind, N., \& Jones, T. (1996). Using SPSS for Windows; analyzing and understanding data. Englewood Cliffs, NJ: Prentice Hall.

Hair, J. F., Anderson, R. E., Tatham, R. L., \& Black, W. C. (1995). Multivariate data analysis. Englewood Cliffs, NJ: Prentice-Hall.

Janssen, J., Kirschner, F., Erkens, G., Kirschner, P. A., \& Paas, F. (2010). Making the black box of collaborative learning transparent: Combining process-oriented and cognitive load approaches. Educational Psychology Review, 22, 139-154. doi:10.1007/s10648-010-9131-x

Kablan, Z., \& Erden, M. (2008). Instructional efficiency of integrated and separated text with animated presentations in computer-based science instruction. Computers \& Education, 51, 660-668. doi:10.1016/j.compedu.2007.07.002

Kalyuga, S., Chandler, P., \& Sweller, J. (2000). Incorporating learner experience into the design of multimedia instruction. Journal of Educational Psychology, 92, 126-136. doi:10.1037/0022-0663.92.1.126

Kalyuga, S., Chandler, P., \& Sweller, J. (2001). Learner experience and efficiency of instructional guidance. Educational Psychology, 21, 523. doi:10.1080/01443410124681

Kalyuga, S., \& Sweller, J. (2004). Measuring knowledge to optimize cognitive load factors during instruction. Journal of Educational Psychology, 96, 534-558. doi:10.1037/0022-0663.96.3.558

Kilıç, E. (2006). Effects of parallel instructional design and task difficulty level on university students' achievement and cognitive load in multimedia learning environment. Unpublished Doctorate Dissertation, Ankara: Ankara University Educational Sciences.

Kirschner, P. (2002). Cognitive load theory: Implications of cognitive load theory on the design of learning. Learning and Instruction, 12, 1-10. doi:10.1016/S0959-4752(01)00014-7

Kirschner, P., Sweller, J., \& Clark, R. (2006). Why minimal guidance during instruction does not work: An analysis of the failure of constructivist, discovery, problem-based, experiential, and inquiry-based teaching. Educational Psychologist, 41, 75-86. doi:10.1207/s15326985ep4102_1

Miller, G. (1956). The magical number seven, plus or minus two: Some limits on our capacity for processing information. Psychological Review, 63, 81-97. doi:10.1037/h0043158

MONE (2005). Ilköğretim matematik dersi öğretim kllavuzu 6-8. siniflar. Ankara: MONE.

NCTM (2000). Principles and standards for school mathematics. New York: National Council of Teachers of Mathematics.

Paas, F. (1992). Training strategies for attaining transfer of problem-solving skill in statistics: A cognitive-load approach. Journal of Educational Psychology, 84, 429-434. doi:10.1037/0022-0663.84.4.429

Paas, F., Renkl, A., \& Sweller, J. (2003). Cognitive load theory: A special issue of educational psychologist. Hillsdale, NJ: Lawrence Erlbaum.

Paas, F., van Gog, T., \& Sweller, J. (2010). Cognitive load theory: New conceptualizations, specifications, and integrated research perspectives. Educational Psychology Review, 22, 115-121. doi:10.1007/s10648-010-9133-8

Paas, F., \& Van Merrienboer, J. (1993). The efficiency of instructional conditions: An approach to combine mental effort and performance measures. Human Factors: The Journal of the Human Factors and Ergonomics Society, 35, 737-743.

Paas, F., \& Van Merrienboer, J. (1994). Variability of worked examples and transfer of geometrical problem-solving skills: A cognitive-load approach. Journal of Educational Psychology, 86, 122-122. doi:10.1037/0022-0663.86.1.122

Paas, F., \& Van Merriënboer, J. (1994). Instructional control of cognitive load in the training of complex cognitive tasks. Educational Psychology Review, 6, 351-371. doi:10.1007/BF02213420

Paas, F., Renkl, A., \& Sweller, J. (2004). Cognitive load theory: Instructional implications of the interaction between information structures and cognitive architecture. Instructional Science, 32, 1-8.
doi:10.1023/B:TRUC.0000021806.17516.d0

Paas, F., Tuovinen, J., Tabbers, H., \& Van Gerven, P. (2003). Cognitive load measurement as a means to advance cognitive load theory. Educational Psychologist, 38, 63-71. doi:10.1207/S15326985EP3801 8

Paas, F., \& Van Merriënboer, J. (1994). Instructional control of cognitive load in the training of complex cognitive tasks. Educational Psychology Review, 6, 351-371. doi:10.1007/BF02213420

Plass, J. L., Moreno, R., \& Brünken, R. (2010). Cognitive load theory. Cambridge: Cambridge University Press.

Pawley, D., Ayres, P., Cooper, M., \& Sweller, J. (2005). Translating words into equations: A cognitive load theory approach. Educational Psychology, 25, 75-97. doi:10.1080/0144341042000294903

Renkl, A., \& Atkinson, R. (2003). Structuring the transition from example study to problem solving in cognitive skill acquisition: A cognitive load perspective. Educational Psychologist, 38, 15-22. doi:10.1207/S15326985EP3801_3

Sezgin, E. (2009). The effects of multimedia courseware designed based on cognitive theory of multimedia learning on cognitive load, performance levels and retention. Unpublished Dissertation Thesis. Adana: Çukurova University.

Sweller, J. (1988). Cognitive load during problem solving: Effects on learning. Cognitive Science, 12, 257-285. doi: $10.1207 / \mathrm{s} 15516709 \operatorname{cog} 1202 \_4$

Sweller, J. (1994). Cognitive load theory, learning difficulty, and instructional design. Learning and Instruction, 4, 295-312. doi:10.1016/0959-4752(94)90003-5

Sweller, J. (2010). Element interactivity and intrinsic, extraneous, and germane cognitive load. Educational Psychology Review, 22, 123138. doi:10.1007/s10648-010-9128-5

Sweller, J., Ayres, P., \& Kalyuga, S. (2011a). Cognitive load theory (Vol. 1). New York: Springer. doi:10.1007/978-1-4419-8126-4

Sweller, J., Ayres, P., \& Kalyuga, S. (2011b). Cognitive load theory in perspective. Cognitive Load Theory, 237-242.

Sweller, J., \& Chandler, P. (1991). Evidence for cognitive load theory. Cognition and Instruction, 8, 351-362. doi:10.1207/s1532690xci0804 5

Sweller, J., \& Cooper, G. (1985). The use of worked examples as a substitute for problem solving in learning algebra. Cognition and Instruction, 2, 59-89. doi:10.1207/s1532690xci0201_3

Tabachnick, B. G., \& Fidell, L. S. (2001). Using multivariate statistics (4th ed.). Needham, MA: Allyn \& Bacon.

Tabbers, H. K., Martens, R. L., \& Merriënboer, J. J. G. (2004). Multimedia instructions and cognitive load theory: Effects of modality and cueing. British Journal of Educational Psychology, 74, 71-81. doi:10.1348/000709904322848824

Tarmizi, R. A., \& Sweller, J. (1988). Guidance during mathematical problem solving. Journal of educational psychology, 80, 400-424. doi: $10.1037 / 0022-0663.80 .4 .424$

Tatar, E., \& Dikici, R. (2008). Matematik Eğitiminde Öğrenme Güçlükleri. Mustafa Kemal Üniversitesi Sosyal Bilimler Enstitüsü Dergisi, 5, 180-193.

Tobias, S., \& Duffy, T. M. (2009). Constructivist instruction. Oxford: Taylor \& Francis.

Tuovinen, J., \& Sweller, J. (1999). A comparison of cognitive load associated with discovery learning and worked examples. Journal of Educational Psychology, 91, 334-341. doi:10.1037/0022-0663.91.2.334

Usiskin, Z. (1995). Why is algebra important to learn. American Educator, 19, 30-37.

Van Gerven, P., Paas, F., Van Merrinboer, J., \& Schmidt, H. (2002). Cognitive load theory and aging: Effects of worked examples on training efficiency. Learning and Instruction, 12, 87-105. doi:10.1016/S0959-4752(01)00017-2

Van Gog, T., Paas, F., \& Van Merriënboer, J. (2004). Process-oriented worked examples: Improving transfer performance through enhanced understanding. Instructional Science, 32, 83-98. doi:10.1023/B:TRUC.0000021810.70784.b0

Van Merrienboer, J. (1997). Training complex cognitive skills. Englewood Cliffs, NJ: Educational Technology Publications. 


\section{A. TAKIR ET AL.}

Van Merriënboer, J., \& Kirschner, P. (2001). Three worlds of instructional design: State of the art and future directions. Instructional Science, 29, 429-441. doi:10.1023/A:1011904127543

Van Merrienboer, J., Kirschner, P., \& Kester, L. (2003). Taking the load off a learner's mind: Instructional design for complex learning. Educational Psychologist, 38, 5-13.

doi:10.1207/S15326985EP3801 2

Van Merriënboer, J., Schuurman, J., De Croock, M., \& Paas, F. (2002). Redirecting learners' attention during training: Effects on cognitive load, transfer test performance and training efficiency. Learning and Instruction, 12, 11-37. doi:10.1016/S0959-4752(01)00020-2
Van Merriënboer, J., \& Sweller, J. (2005). Cognitive load theory and complex learning: Recent developments and future directions. Educational Psychology Review, 17, 147-177. doi:10.1007/s10648-005-3951-0

Yayan, B. (2003). A cross-cultural comparison of mathematics achievement in the third international mathematics and science study-repeat (TIMSS-R). Ankara: Middle East Technical University.

Zhu, X., \& Simon, H. A. (1987). Learning mathematics from examples and by doing. Cognition and Instruction, 4, 137-166. doi:10.1207/s1532690xci0403 1 